\title{
AVALIAÇÃO DA EFICIÊNCIA DE SANITIZANTES SOBRE BACTÉRIAS ESPORULADAS ISOLADAS DE LEITE UHT INTEGRAL
}

\section{Evaluation of sanitizers efficiency over spore forming bacteria isolated from whole UHT milk}

\author{
Edite Andrade Costa ${ }^{1}$, Leonardo Justino Carioca ${ }^{2}$, Valdeir Viana Freitas ${ }^{2}$, \\ Maurilio Lopes Martins ${ }^{3 *}$, Aurélia Dornelas de Oliveira Martins ${ }^{3}$, \\ Cláudia Lúcia de Oliveira Pinto ${ }^{4}$
}

\begin{abstract}
RESUMO
A implementação de medidas preventivas de contaminações do leite com bactérias esporuladas é imprescindível considerando que esses microrganismos são produtores de enzimas proteolíticas e lipolíticas termoresistentes associadas a problemas tecnológicos como off flavors, coagulação doce e gosto amargo em leite e derivados, dentre outros. Dentre essas medidas, pode-se citar tipo de sanitizante e as condições de uso como concentração, tempo de contato e temperatura. Objetivou-se avaliar a eficiência de sanitizantes comumente empregados na indústria de laticínios sobre bactérias esporuladas isoladas de leite UHT. Empregou-se o teste de suspensão para avaliar a eficiência de soluções de hipoclorito de sódio, biguanida, ácido peracético e peróxido de hidrogênio sobre 18 estirpes de bactérias esporuladas do gênero Bacillus isoladas de leite UHT integral. Embora a maior ação sanitizante tenha sido observada para a biguanida, nenhum dos sanitizantes foi efetivo nas condições avaliadas, considerando que os valores médios observados de redução decimal (RD) foram inferiores a cinco ciclos logarítmicos ou a 99,999\%. A efetividade de sanitizantes é um fator primordial para o controle de contaminações de natureza
\end{abstract}

1 Universidade Estadual do Norte Fluminense Darcy Ribeiro, Campos dos Goytacazes, RJ, Brasil.

2 Universidade Federal de Viçosa (UFV), Departamento de Tecnologia de Alimentos, Viçosa, MG, Brasil.

3 Instituto Federal de Educação, Ciência e Tecnologia do Sudeste de Minas Gerais, Campus Rio Pomba, Av. Dr. José Sebastião da Paixão, s/n, Bairro Lindo Vale, 36180-000, Rio Pomba, MG, Brasil. E-mail: maurilio.martins@ifsudestemg.edu.br

4 Empresa de Pesquisa Agropecuária de Minas Gerais (EPAMIG), Viçosa, MG, Brasil.

* Autor para correspondência. 
microbiana na indústria de laticínios. Assim, é fundamental a definição das condições ideais de uso destes produtos.

Palavras-chave: leite UHT; esporos; sanitização.

\begin{abstract}
It is known that sporulated bacteria produce proteolytic and lipolytic thermoresistant enzymes associated with technological problems such as off-flavors, age gelation and bitter taste in milk and dairy products. Preventive measures to avoid contamination of milk must be taken in consideration, e.g., the employment of a certain type of sanitizing agent, its conditions of use, concentration, contact time and temperature. The aim of this work was to evaluate the sanitation efficiency of workers of the dairy industry in relation to sporulated bacteria isolated from UHT milk. The suspension test was used to evaluate the efficiency of solutions of sodium hypocholite, biguanide, peracetic acid and hydrogen peroxide against 18 strains of Bacillus sp. isolated from whole UHT milk. Although the biguanide resulted in significant decimal reduction, none of the sanitizing agents studied was effective under the evaluated conditions. The average decimal reduction values obtained were below 5 log cycles (99.999\%). The effectiveness of the sanitizing agent is a primary factor in order to control the contaminations within the dairy industry. Thus, it is essential to define the ideal conditions of use of these agents.
\end{abstract}

Keywords: UHT milk; spore; sanitization.

\section{INTRODUÇÃO}

Define-se leite UHT (Ultra High Temperature) ou UAT (Ultra Alta Temperatura) ou longa vida o leite homogeneizado submetido a tratamento térmico de fluxo contínuo entre $130{ }^{\circ} \mathrm{C}$ e $150{ }^{\circ} \mathrm{C}$, por 2 a 4 segundos e, imediatamente, resfriado a temperatura inferior a $32{ }^{\circ} \mathrm{C}$ e envasado, sob condições assépticas, em embalagens esterilizadas e hermeticamente fechadas (BRASIL, 1997). A tendência do mercado pelo consumo de produtos alimentícios de boa qualidade e de vida de prateleira longa culminou no interesse de muitas indústrias de laticínios pela produção de leite UHT. Esse processo permite a conservação do leite à temperatura ambiente $\mathrm{e}$ o prolongamento da vida útil que, em geral, é de até cinco meses. Porém, podem ocorrer alterações ao longo do armazenamento do produto, associadas à atividade de enzimas ter- morresistentes produzidas por bactérias psicrotróficas e esporuladas, organismos esses limitantes da qualidade do leite. Os esporos bacterianos são estruturas especiais, resistentes, dormentes, formados no interior de uma célula procariota e tem como função a proteção contra condições ambientais adversas. As bactérias termofílicas e mesofílicas formadoras de esporos são de grande importância do ponto de vista da esterilização comercial, associada a sua termorresistência.

A contaminação do leite UHT por bactérias esporuladas representa um dos principais entraves na sua cadeia produtiva, pois essas bactérias produzem enzimas termoestáveis e são capazes de formar biofilmes. Essas bactérias têm como habitat o solo e as pastagens. Assim, sua presença no leite é indicativa do emprego de condições higiênicas inapropriadas de produção e processamento. Os gêneros bacterianos formadores de esporos 
incluem: Bacillus, Clostridium, Sporosarcina, Sporolactobacillus, Thermoactinomyces e Paenibacillus. Bactérias esporuladas dos gêneros Bacillus e Paenibacillus são os principais microrganismos que limitam a qualidade do leite fluido produzido em condições higiênicas inadequadas. Esses organismos habitam, comumente, solo e pastagens (HUCK et al., 2007; IVY et al., 2012).

A boa qualidade microbiológica da matéria-prima é um pré-requisito para a obtenção de produto com alto padrão de qualidade e prevenção de perdas associadas à atividade de enzimas termoestáveis durante a sua vida útil. Essas enzimas causam problemas tecnológicos, como coagulação doce, alterações sensoriais (off flavors, gosto amargo) e instabilidade térmica. A ocorrência de lipólise no leite resulta da ação lípases naturais e/ou microbianas caracterizadas pela hidrólise de triglicérides, constituintes da gordura, com liberação de ácidos graxos de cadeia curta como butírico, capróico, caprílico e cáprico, principais responsáveis por odores desagradáveis no leite. As proteases, mesmo em concentrações baixas, apresentam atividade hidrolítica, o que causa defeitos em produtos de vida de prateleira longa, a exemplo do leite UHT e do leite em pó.

Várias mudanças estruturais ocorrem na célula vegetativa até a sua transformação em esporo como produção de enzimas e metabólitos e desaparecimento de vários componentes celulares. Essa diferenciação promove a ativação de muitos genes e modificação da transcrição pela enzima RNA polimerase. Estruturalmente, os esporos são muito complexos, possuem várias camadas dispostas concentricamente que compõem a estrutura externa. O core é o núcleo central parcialmente desidratado, onde maior parte da água foi substituída por cálcio e ácido dipicolínico. O núcleo é envolvido pela membrana interna representada por uma fina camada da membrana citoplasmática da célula vegetativa. Externamente encontra-se o córtex constituído de peptidoglicano frouxamente associado, seguido da membrana externa e exósporo, um envoltório fino e delgado formado por lipoproteínas. A maioria destas estruturas é rapidamente perdida no processo de germinação: o revestimento é desfeito e o córtex é degradado por hidrolases da parede celular. A membrana interna dos esporos torna-se a membrana plasmática, enquanto que a membrana externa é perdida durante a maturação dos esporos (McKENNEY; DRIKS; EICHENBERGER, 2013). Na indústria de laticínios, o emprego de procedimentos inadequados de limpeza e de sanitização dos equipamentos e a microbiota contaminante do ambiente de processamento são consideradas as principais causas de contaminação dos produtos com microrganismos deterioradores e patogênicos.

Desta forma, ressalta-se a importância do emprego de procedimentos de higienização eficientes com foco na prevenção de contaminações de natureza microbiana. Os sanitizantes utilizados na indústria de alimentos devem ser adquiridos com base na sua atividade antimicrobiana, ação sobre equipamentos e superfícies, tratabilidade dos efluentes industriais gerados e, também, sobre os os operadores (EVANGELISTA, 2000). Associado a maior capacidade de adesão dos esporos bacterianos comparada à células vegetativas, à sua alta hidrofobicidade e morfologia, a escolha de sanitizantes eficientes contra esporos é necessária para fins de prevenção de contaminações do leite processado. Dentre os sanitizantes químicos com capacidade esporicida mais utilizados estão biguanida, os compostos clorados inorgânicos e orgânicos, ácido peracético e peróxido de hidrogênio. No presente trabalho, objetivou-se avaliar a eficiência de sanitizantes usados na indústria de laticínios para inativar bactérias esporuladas isoladas de leite UHT. 


\section{MATERIAL E MÉTODOS}

A pesquisa foi realizada no Laboratório de Microbiologia de Alimentos do Departamento de Ciência e Tecnologia de Alimentos do Instituto Federal do Sudeste de Minas Gerais, campus Rio Pomba (IF Sudeste $\mathrm{MG}$ ). Os experimentos foram realizados em três repetições.

\section{Bactérias esporuladas}

Avaliou-se a eficiência de sanitizantes para inativação de 18 estirpes bacterianas, esporuladas, mesófilas, isoladas de leite UHT integral por Souza et al. (2013). Inicialmente, os isolados foram ativados em caldo $\mathrm{BHI}$, por 24 horas, a $34{ }^{\circ} \mathrm{C}$. A pureza dos isolados foi confirmada por meio de semeadura em Ágar Infusão de Cérebro e Coração (BHI) pelo método de estrias compostas e incubação por 18 horas, a $34{ }^{\circ} \mathrm{C}$.

\section{Avaliação da eficiência de sanitizantes}

A partir de culturas puras, inoculou-se, separadamente, uma colônia de cada isolado bacteriano em tubos de ensaio contendo caldo BHI. Procedeu-se incubação a $34{ }^{\circ} \mathrm{C}$, por 18 horas. A avaliação da eficiência dos sanitizantes para inativação dos isolados foi realizada por meio do teste de suspensão descrito por Andrade (2008). Avaliaram-se os seguintes sanitizantes: um composto clorado orgânico, biguanida, ácido peracético e peróxido de hidrogênio, sanitizantes químicos amplamente empregados na indústria de laticínios.

\section{Determinação da população inicial de bactérias esporuladas}

Realizou-se diluições sucessivas (entre $10^{-1}$ a $\left.10^{-8}\right)$ a partir de uma alíquota de $1 \mathrm{~mL}$ da suspensão bacteriana, previamente ativada como descrito no item anterior, em solução salina peptonada. Em seguida, $1 \mathrm{~mL}$ das diluições $10^{-6}, 10^{-7}$ e $10^{-8}$ foram inoculadas, em duplicata, em Ágar BHI. A incubação foi realizada a $34{ }^{\circ} \mathrm{C}$ por 24 horas e as placas foram contadas e o resultado expresso em $\log \mathrm{UFC} / \mathrm{mL}$.

\section{Determinação do número de reduções decimais (RD) de bactérias esporuladas}

Adicionou-se $1 \mathrm{~mL}$ da suspensão bacteriana em $99 \mathrm{~mL}$ das soluções sanitizantes: hipoclorito de sódio $(200 \mathrm{mg} / \mathrm{L})$, biguanida $(1.500 \mathrm{mg} / \mathrm{L})$, ácido peracético $(2.500 \mathrm{mg} / \mathrm{L})$ e peróxido de hidrogênio $(10.000 \mathrm{mg} / \mathrm{L})$. Todas as soluções foram aferidas para $\mathrm{pH}$ 7,0. Procedeu-se então a homogeneização e incubação por 10 minutos em estufa tipo BOD, a $20^{\circ} \mathrm{C}$. Em seguida, transferiu-se $1 \mathrm{~mL}$ para $9 \mathrm{~mL}$ de uma solução neutralizante de tiossulfato de sódio $\left(\mathrm{Na}_{2} \mathrm{SO}_{3}\right)$ 0,25\% e realizaram-se diluições sucessivas $\left(10^{-3}, 10^{-4} \mathrm{e}\right.$ $10^{-5}$ ) e plaqueamento em duplicata em Ágar BHI. As placas foram incubadas a $34{ }^{\circ} \mathrm{C}$ por 24 horas. Após, realizou-se a enumeração das colônias. Os resultados foram expressos em $\log \mathrm{UFC} / \mathrm{mL}$.

A eficiência dos sanitizantes foi avaliada por meio do cálculo do número de reduções decimais (RD), representada pela diferença entre o logaritmo decimal da população inicial de células bacterianas e o logaritmo decimal de células bacterianas sobreviventes após exposição as soluções sanitizantes. Considerou-se como indicador de efetividade do produto uma redução decimal de pelo menos cinco ciclos logarítmicos ou 99,999\% da população bacteriana, após contato do microrganismo com a solução pelo tempo recomendado pelos fornecedores a $20^{\circ} \mathrm{C}$ (ANDRADE, 2008).

\section{Analises Estatística}

Os experimentos foram realizados em três repetições. Inicialmente, foi conduzido 
um experimento segundo o delineamento em blocos casualizados (DBC) a fim de comparar as médias da população inicial com as médias das reduções decimais promovidas pelos sanitizantes. Além disso, foi utilizado o delineamento inteiramente casualizado (DIC) também com três repetições para comparar as reduções decimais de cada isolado quando se utilizou um mesmo sanitizante. Os resultados foram analisados por meio de análise de variância (ANOVA) e teste de Tukey para comparações entre as médias.

Todos os procedimentos estatísticos foram realizados considerando o nível de $5 \%$ de probabilidade e utilizando o programa estatístico R com auxílio do pacote ExpDes (FERREIRA; CAVALCANTI; NOGUEIRA, 2011).

\section{RESULTADOS E DISCUSSÃO}

Constatou-se maior redução decimal da contagem inicial com a biguanida $(1.500$ $\mathrm{mg} / \mathrm{L}$ ), entretanto, inferior a 5RD (Tabela 1). Em estudo de Dawson et al. (2011) foi observado que solução de biguanida em concentração de $50 \%$ superior a avaliada no presente estudo, por tempo de contato de 30 minutos foi efetiva para inativação de esporos de Clostridium difficile dos ribotipos 012, 017 e 027, sendo o último ribotipo mais resistente. Ferreira (2012) observou que biguanida na concentração de $160 \mathrm{mg} / \mathrm{L}$, por 3 minutos de contato não foi efetiva para inativação de esporos de $C$. difficile com redução decimal de esporos viáveis inferior à $10 \%$, mas foi efetiva na inativação de $C$. difficile na forma vegetativa.

As soluções de hipoclorito de sódio (200 $\mathrm{mg} / \mathrm{L})$ e de ácido peracético $(2.500 \mathrm{mg} / \mathrm{L})$ apresentaram baixa efetividade sobre os isolados de Bacillus e não difeririam ( $\mathrm{p}>0,05)$ quanto aos valores de RD (Tabela 1). Esses resultados são condizentes com os constatados por Moraes (1996) que observaram valor de redução decimal de 2,2 para cinco isolados de bactérias aeróbias mesófilas esporuladas isoladas de superfícies de equipamentos de abatedouro de aves quando expostos a soluções de ácido peracético (300 mg/L), por 30 minutos. Entretanto, Block (2004), ao avaliar um produto à base de ácido peracético na concentração de $0,26 \%$, concentração esta próxima a avaliada na presente pesquisa, constatou redução de 6 ciclos logarítmicos da população inicial de esporos viáveis, próxima a $100 \%$ em relação a população inicial de esporos, que era de, aproximadamente, 5, $0 \mathrm{x}$ $10^{6} \mathrm{UFC} / \mathrm{mL}$.

Constatou-se maiores valores de RD para as soluções de ácido peracético e hipoclorito de sódio em relação à peróxido de

Tabela 1 - Média da contagem inicial de bactérias esporuladas e de reduções decimais (RD) após contato com as soluções sanitizantes

\begin{tabular}{lcc}
\hline & $\log \mathrm{UFC} / \mathrm{mL}$ & $\mathrm{RD}(\log \mathrm{UFC} / \mathrm{mL})$ \\
\hline Contagem inicial & $8.02^{\mathrm{a}}$ & \\
\hline Sanitizantes & & \\
\hline Hipoclorito de sódio & $4,59^{\mathrm{b}}$ & $3.42^{\mathrm{a}}$ \\
Ácido Peracético & $4,65^{\mathrm{b}}$ & $3.37^{\mathrm{a}}$ \\
Biguanida & $3,75^{\mathrm{c}}$ & $4,26^{\mathrm{b}}$ \\
Peróxido de Hidrogênio & $5,54^{\mathrm{d}}$ & $2.47^{\mathrm{c}}$ \\
\hline
\end{tabular}

Médias seguidas de mesma letra na coluna não diferiram entre si a 5\% de probabilidade. 
hidrogênio (Tabela 1). Ao contrário, Rosa (2009), ao avaliar o controle dos esporos de Clostridium estertheticum e Clostridium gasigenes in vitro, verificaram que sanitizantes à base de ácido peracético a $500 \mathrm{mg} / \mathrm{L}$, pH 2,9 e peróxido de hidrogênio a $200 \mathrm{mg} / \mathrm{L}$,
pH 1,7 apresentaram melhor ação esporicida sobre estas bactérias em relação ao hipoclorito de sódio a $100 \mathrm{mg} / \mathrm{L}$, por 15 minutos, pH 10,8 .

Isolados de Bacillus da mesma espécie apresentaram diferenças quanto a sensibili-

Tabela 2 - Comparação da eficiência de sanitizantes, expressa em reduções decimais (RD), sobre espécies de Bacillus isoladas de leite UHT integral

\begin{tabular}{|c|c|c|c|c|c|c|}
\hline Isolado & $\begin{array}{l}\text { Código/ } \\
\text { Isolado }\end{array}$ & Identificação & $\begin{array}{l}\text { Hipoclorito } \\
\text { de Sódio } \\
(200 \mathrm{mg} / \mathrm{L})\end{array}$ & $\begin{array}{c}\text { Biguanida } \\
(1.500 \mathrm{mg} / \mathrm{L})\end{array}$ & $\begin{array}{c}\text { Ácido } \\
\text { Peracético } \\
(2.500 \mathrm{mg} / \mathrm{L})\end{array}$ & $\begin{array}{l}\text { Peróxido de } \\
\text { hidrogênio } \\
(10.000 \mathrm{mg} / \mathrm{L})\end{array}$ \\
\hline 4 & EB13 & $\begin{array}{l}\text { Bacillus subtilis / } \\
\text { amyloliquefaciens }\end{array}$ & $4,2^{\mathrm{cd}}$ & $4,0^{\mathrm{ab}}$ & $3,3^{\mathrm{a}}$ & $2,6^{\mathrm{ab}}$ \\
\hline 6 & EE12(6) & Bacillus pumilus & $3,7^{\text {bcd }}$ & $4,7^{\mathrm{ab}}$ & $3,8^{\mathrm{a}}$ & $5,0^{\mathrm{c}}$ \\
\hline 7 & $\mathrm{P} 20$ & $\begin{array}{l}\text { Bacillus subtilis / } \\
\text { amyloliquefaciens }\end{array}$ & $4,1^{\text {bcd }}$ & $5,3^{\mathrm{ab}}$ & $4,2^{\mathrm{a}}$ & $2,4^{\mathrm{ab}}$ \\
\hline 3 & EA26 & $\begin{array}{l}\text { Brevibacillus } \\
\text { não reativo }\end{array}$ & $3,4^{\mathrm{abcd}}$ & $3,5^{\mathrm{a}}$ & $3,0^{\mathrm{a}}$ & $1,9^{\mathrm{a}}$ \\
\hline 2 & EA15 & Bacillus pumilus & $4,8^{\mathrm{d}}$ & $4,6^{\mathrm{ab}}$ & $3,8^{\mathrm{a}}$ & $3,1^{\mathrm{ab}}$ \\
\hline 1 & $\mathrm{EI} 2$ & Bacillus megaterium & $4,0^{\text {bcd }}$ & $3,0^{\mathrm{a}}$ & $3,3^{\mathrm{a}}$ & $1,6^{\mathrm{a}}$ \\
\hline 5 & EA22 & Bacillus firmus & $3,3^{\mathrm{abcd}}$ & $4,3^{\mathrm{ab}}$ & $3,6^{\mathrm{a}}$ & $1,6^{\mathrm{a}}$ \\
\hline 16 & EL23 & $\begin{array}{l}\text { Bacillus subtilis / } \\
\text { amyloliquefaciens }\end{array}$ & $3,0^{\mathrm{abcd}}$ & $3,5^{\mathrm{a}}$ & $3,6^{\mathrm{a}}$ & $3,0^{\mathrm{ab}}$ \\
\hline 9 & EE21 & $\begin{array}{l}\text { Bacillus mycoide } \\
\text { e Bacillus cereus }\end{array}$ & $2,6^{\mathrm{abc}}$ & $4,1^{\mathrm{ab}}$ & $2,3^{\mathrm{a}}$ & $2,5^{\mathrm{ab}}$ \\
\hline 11 & EL 12(2) & $\begin{array}{l}\text { Bacillus subtilis / } \\
\text { amyloliquefaciens }\end{array}$ & $4,6^{\mathrm{d}}$ & $6,0^{\mathrm{b}}$ & $4,3^{\mathrm{a}}$ & $4,2^{\mathrm{ab}}$ \\
\hline 18 & $\mathrm{EC} 22$ & $\begin{array}{l}\text { Bacillus subtilis / } \\
\text { amyloliquefaciens }\end{array}$ & $2,9^{\mathrm{abcd}}$ & $4,4^{\mathrm{ab}}$ & $3,5^{\mathrm{a}}$ & $1,7^{\mathrm{a}}$ \\
\hline 15 & EM23 & $\begin{array}{l}\text { Bacillus subtilis / } \\
\text { amyloliquefaciens }\end{array}$ & $2,6^{\mathrm{abc}}$ & $4,4^{\mathrm{ab}}$ & $3,1^{\mathrm{a}}$ & $1,1^{\mathrm{a}}$ \\
\hline 17 & EB12 & $\begin{array}{l}\text { Bacillus subtilis / } \\
\text { amyloliquefaciens }\end{array}$ & $1,6^{\mathrm{a}}$ & $3,3^{\mathrm{a}}$ & $2,3^{\mathrm{a}}$ & $1,7^{\mathrm{a}}$ \\
\hline 10 & EE21(5) & Bacillus licheniformis & $4,4^{\mathrm{cd}}$ & $4,2^{\mathrm{ab}}$ & $2,6^{\mathrm{a}}$ & $2,5^{\mathrm{ab}}$ \\
\hline 12 & $\mathrm{EC} 12$ & $\begin{array}{l}\text { Bacillus subtilis / } \\
\text { amyloliquefaciens }\end{array}$ & $2,1^{\mathrm{ab}}$ & $4,8^{\mathrm{ab}}$ & $3,8^{\mathrm{a}}$ & $2,1^{\mathrm{a}}$ \\
\hline
\end{tabular}

Médias seguidas de mesma letra na coluna para cada sanitizante não diferem entre si a 5\% de probabilidade. 
dade aos sanitizantes, provavelmente, associado às características genéticas especificas (Tabela 2).

Em pesquisa realizada por Setlow e Setlow (1993) foi observada resistência de esporos de B. subtilis à solução de peróxido de hidrogênio $4 \mathrm{M}$ após exposição das células por $20 \mathrm{~min}$. Shin et al. (1994) constataram uma redução de 4,7 log de esporos de $B$. subtilis ao utilizarem $15 \%$ de peróxido de hidrogênio a $60{ }^{\circ} \mathrm{C}$, por $30 \mathrm{~min}$. Orr e Beuchat (2000) constataram reduções decimais (log $\mathrm{UFC} / \mathrm{mL}$ ) de Alicyclobacillus acidoterrestris de aproximadamente 2,4; 5,4 e > 6,0 em soluções de hipoclorito nas concentrações de 200, 500 e > $1000 \mathrm{mg} / \mathrm{L}$ de cloro livre após 10 minutos, respectivamente.

Em pesquisa realizada por Marquezini, Bromberg e Oliveira (2012) foi observado que sanitizantes à base de quaternário de amônio nas concentrações $900 \mathrm{mg} / \mathrm{L}$ e 4.500 $\mathrm{mg} / \mathrm{L}$ promoveram uma redução de 8 ciclos $\log$ em suspensões de $C$. estertheticum e $C$. gasigenes, nos primeiros 5 minutos de contato. Ácido peracético e hipoclorito de sódio na concentração de $500 \mathrm{mg} / \mathrm{L}$ promoveram uma redução de 6 ciclos log com 15 min de contato.

As concentrações avaliadas de ácido peracético $(2.500 \mathrm{mg} / \mathrm{L})$ e de hipoclorito de sódio $(200 \mathrm{mg} / \mathrm{L})$ no presente estudo e também suas condições de uso como tempo de contato, $\mathrm{pH}$ e espécies avaliadas foram diferentes dos estudos citados, o que pode explicar a diferença nos resultados.

Segundo Andrade e colaboradores (2008), as condições de uso dos sanitizantes empregados para controle de bactérias esporuladas em superfícies na indústria de alimentos são: hipoclorito de sódio na concentração de 100 mg/L, pH 10; ácido peracético na concentração de $60 \mathrm{mg} / \mathrm{L}, \mathrm{pH}$ 3; peróxido de hidrogênio na concentração de $50.000 \mathrm{mg} / \mathrm{L}, \mathrm{pH} 4$ e clorhexidina na concentração de 100 mg/L, pH 4. Segundo os autores, hipoclorito de sódio possui eficácia moderada. Entretanto, no presente estudo não foi constatada diferença significativa entre os sanitizantes, hipoclorito de sódio e ácido peracético sendo que o peróxido de hidrogênio apresentou menor eficácia. Andrade e colaboradores (2008) observaram redução decimal de 5,0 e de 2,8, respectivamente, na população de B. subtilis após exposição, por 5 minutos, à solução com concentração de cloro residual de $200 \mathrm{mg} / \mathrm{L}$, pH 7,8 , a $27^{\circ} \mathrm{C}$ e, à solução de ácido peracético $300 \mathrm{mg} / \mathrm{L}$, $\mathrm{pH} 2,5$, a $35^{\circ} \mathrm{C}$, respectivamente.

\section{CONCLUSÕES}

Embora a biguanida tenha apresentado maior valor de redução decimal, nenhum dos sanitizantes (biguanida, ácido peracético, hipoclorito de sódio e peróxido de hidrogênio) foi eficiente para inativação de Bacillus nas condições avaliadas, com valores de redução decimal inferiores a 5, ou a 99,999\% da população bacteriana. Isolados da mesma espécie diferiram quanto a sensibilidade aos sanitizantes. A efetividade de sanitizantes é um fator primordial para o controle de contaminações de natureza microbiana na indústria de laticínios. Assim, é fundamental a definição das condições ideais de uso destes produtos.

\section{AGRADECIMENTOS}

À Fundação de Amparo à Pesquisa de Minas Gerias (FAPEMIG), ao Instituto Federal de Educação, Ciência e Tecnologia do Sudeste de Minas Gerais, campus Rio Pomba, e ao grupo PET-Ciências Agrárias pelo apoio financeiro.

\section{REFERÊNCIAS}

ANDRADE, N. J. Higienização na Indústria de Alimentos: avaliação e controle da 
adesão e formação de biofilmes bacterianos. São Paulo: Varela, 2008. 400p.

BLOCK, C. The effect of Perasafe and sodium dichloroisocyanurate (NaDCC) against spores of Clostridium difficile and Bacillus atrophaeus on stainless steel and polyvinyl chloride surfaces. Journal of Hospital Infection, v. 57, n. 2, p. 144-148, 2004.

BRASIL. Ministério da Agricultura, Pecuária e Abastecimento. Departamento de Inspeção de Produtos de Origem Animal. Portaria ${ }^{\circ}$ 370, de 4 de setembro de 1997. Regulamento técnico para fixação de identidade e qualidade do leite UHT (UAT). Diário Oficial da República Federativa do Brasil, Brasília, 8 set. 1997. Seção I.

DAWSON, L.F. et al. Hypervirulent Clostridium difficile PCR-ribotypes exhibit resistance to widely used disinfectants. PLOS One, v. 6, n. 10, e 25754, 2011.

EVAngelista, J. Tecnologia de Alimentos. São Paulo: Atheneu, 2000. 652p.

FERREIRA, T. G. Efeito de desinfetantes hospitalares sobre células vegetativas e esporos de ribotipos de Clostridium difficile isolados exclusivamente no Brasil. 2012. 95f. Dissertação (Mestrado em Ciências Aplicadas a Produtos para a Saúde) - Universidade Federal Fluminense, Rio de Janeiro, 2012 .

FERREIRA, E. B. et al. Experimental Designs: um pacote $\mathrm{R}$ para análise de experimentos. Revista de Estatística da UFOP, v. 1, n. 1, p. 1-9, 2011.

HUCK, J. R. et al. Tracking spore-forming bacterial contaminants in fluid milk-processing systems. Journal of Dairy Science, v. 90, n. 10, p. 4872-4883, 2007.
IVY, R. A. et al. Identification and characterization of psychrotolerant sporeformers associated with fluid milk production and processing. Applied and Environmental Microbiology, v. 78, n. 6, p. 1853-1864, 2012.

MARQUEZINI, M. G. et al. Avaliação da sensibilidade de Clostridium estertheticum e Clostridum gasigenes a sanitizantes empregados na indústria de carnes. In: $\mathrm{CON}$ GRESSO LATINO AMERICANO DE MICROBIOLOGIA, 21., 2012. São Paulo. Anais eletrônicos... São Paulo, 2012. Disponível em: <http://www.sbmicrobiologia.org.br/ cdlatino/resumos/R0597-2.html>. Acesso em: 28 maio 2015.

McKENNEY, P. T. et al. The Bacillus subtilis endospore: assembly and functions of the multilayered coat. Nature Reviews Microbiology, v. 11, n. 1, p. 33-45, 2013.

MORAES, M. S. V. Isolamento de esporos aeróbios mesófilos e termófilos em equipamentos de abatedouro de aves e avaliação de suas resistências a sanificantes químicos. 1996. 62f. Dissertação (Mestrado em Ciência e Tecnologia de Alimentos) - Universidade Federal de Viçosa, Viçosa, 1996.

ORR, R. V; BEUCHAT, L. R. Efficacy of disinfectants in killing spores of Alicyclobacillus acodoterrestris and performance of media for supporting colony development by survivors. Journal of Food Protection, v. 63, n. 8, p. 1117-1122, 2000.

ROSA, V. P. Clostridium estertheticum e Clostridium gasigenes: detecção, isolamento, rastreamento e controle no processamento de carne bovina resfriada embalada a vácuo. 2009. 181f. Tese (Doutorado em Tecnologia de Alimentos) - Universidade 
Universidade Estadual de Campinas, Campinas, 2009.

SETLOW, B., SETLOW, P. Binding of small, acid-soluble spore proteins to DNA plays a significant role in the resistance of Bacillus subtilis spores to hydrogen peroxide. Applied and Environmental Microbiology, v. 59, n. 10, p. 3418-3423, 1993.

SHIN, S. Y. et al. Microscopic and thermal characterization of hydrogen peroxide killing and lysis of spores and protec- tion by transition metal ions, chelators, and anti oxidants. Applied and Environmental Microbiology, v. 60, n. 9, p. 3192-3197, 1994.

SOUZA, L. V. et al. Identificação de bactérias esporuladas isoladas de leite UHT processado em indústrias do estado de Minas Gerais, Brasil. In: SIMPÓSIO LATINO AMERICANO DE CIENCIA DE ALIMENTOS, 10., 2013, Campinas. Anais... Campinas: FEA/UNICAMP; SLACA, 2013. 1 CD-ROM. 